\title{
Overexpression of Mannitol-1-Phosphate Dehydrogenase Increases Mannitol Accumulation and Adds Protection Against Chilling Injury in Petunia
}

\author{
Yu-Jen Chiang, C. Stushnoff' ${ }^{1}$, and A.E. McSay \\ Department of Horticulture and Landscape Architecture, Colorado State University, Fort Collins, \\ CO 80523
}

\author{
M.L. Jones \\ Department of Horticulture and Crop Science, The Ohio State University, Wooster, OH 44691
}

H.J. Bohnert

Department of Plant Biology and Crop Sciences, University of Illinois, Urbana, IL 61801

AdDitional INDEX wORDs. chilling injury, raffinose, osmoprotectant

\begin{abstract}
Petunia $\times$ hybrida (Hook) Vilm. cv. Mitchell was transformed with an $E$. coli gene encoding mannitol-1phosphate dehydrogenase $(m t l D)$. Four plant lines that grew on kanamycin and contained the $m t l D$ transgene were identified. Two of these lines contained high levels of mannitol [high-mannitol lines M3 and M8; mean mannitol = 3.39 $\mu \mathrm{mol}^{-} \mathrm{g}^{-1}$ dry weight (DW)] compared to nontransformed wild-type plants $\left(0.86 \mu \mathrm{mol} \cdot \mathrm{g}^{-1} \mathrm{DW}\right)$, while two lines had mannitol levels similar to wild-type plants (low-mannitol lines $\mathrm{M} 2$ and M9; mean mannitol $=1.05 \mu \mathrm{mol} \cdot \mathrm{g}^{-1} \mathrm{DW}$ ). Transgenic and control plants were subjected to chilling stress $\left(3 \pm 0.5{ }^{\circ} \mathrm{C}\right.$ day $/ 0 \pm 0.5{ }^{\circ} \mathrm{C}$ night, 12 -hour photoperiod and $75 \%$ relative humidity) to evaluate the role of mannitol in chilling tolerance. Based upon foliage symptoms and membrane leakage after a 3-week chilling treatment, the high-mannitol containing lines, M3 and M8, were more tolerant of chilling stress than the low-mannitol containing transgenic lines, M2 and M9, and wild-type. Under nonchilling conditions mannitol was the only carbohydrate that differed among transgenic lines, but all carbohydrates were present. When subjected to chilling stress, mannitol levels dropped by $75 \%$, sucrose by $52 \%$, and inositol by $54 \%$ in the low-mannitol lines (M2 and M9). In M3 and M8, the high-mannitol lines, mannitol levels decreased by $36 \%$, sucrose by $25 \%$, and inositol by $56 \%$, respectively. Raffinose increased 2- to 3-fold in all lines following exposure to low-temperature chilling stress. In the higher mannitol lines only $0.04 \%$ to $0.06 \%$ of the total osmotic potential generated from all solutes could be attributed to mannitol, thus its action is more like that of an osmoprotectant rather than an osmoregulator. This study demonstrates that metabolic engineering of osmoprotectant synthesis pathways can be used to improve stress tolerance in horticultural crops.
\end{abstract}

Chilling injury (CI) caused by exposure of plants to low, but nonfreezing, temperatures has long been known to result in physiological dysfunction (Saltveit, 2000). While CI symptoms vary with plant species, cultivars, tissues, and growth stages, they generally develop rapidly after transfer of plants to nonchilling temperatures. Environmental factors such as light intensity, relative humidity and growth conditions prior to chilling can also affect the development of CI. Symptoms related to CI include reduced or retarded germination and seedling development, wilting, tissue chlorosis and necrosis, increased electrolyte leakage caused by altered membranes, imbalances in metabolism, and accelerated senescence (Kuk et al., 2003; Saltveit and Morris, 1990), all of which may impair optimum growth, development, and quality of susceptible horticultural crops.

Lyons (1973) proposed that membrane phase transitions observed at CI temperatures represented a primary physiological event that triggered the development of symptoms. For several good reasons, Saltveit (2000) in a comprehensive review of CI, effectively argued that a new paradigm would be more appropri-

Received for publication 2 June 2004. Accepted for publication 4 Dec. 2004. Funding was provided by the Colorado Agricultural Experiment Station (project 690).

1Corresponding author: e-mail stushnof@lamar.colostate.edu ate. The new paradigm replaces the phase transition as a single event with contributions of a number of factors each conferring a small level of tolerance to resistance. Saltveit (2000) argues that chilling tolerance evolved in diverse unrelated species, independently by a number of different mechanisms. Thus, it is more likely that several small changes accumulated in tolerant species, and that it would be more productive to sequentially identify and characterize mechanisms for these factors rather than search for a primary cause of chilling tolerance in all plants.

The occurrence of photo-oxidative stress and generation of reactive oxygen species (ROS) in plant tissues chilled for prolonged periods have been suggested as possible causes of impaired photosynthetic electron transport (Walker et al., 1991) and of membrane peroxidation in chilling-sensitive plants (Burden et al., 1994; Prasad et al., 1994; Wise and Naylor, 1987). ROS are also generated in plant cells under normal growth conditions, but damage is minimized by the production of antioxidants such as glutathione, beta-carotene, ascorbate, and/or numerous phenolic compounds. Antioxidative enzymes such as superoxide dismutase, ascorbate peroxidase, and glutathione reductase also serve to detoxify free radicals (Alscher et al., 1991). In support of the role of ROS in chilling tolerance, Kerdnaimongkol and Woodson (1999) demonstrated that transgenic tomato (Lycopersicon esculentum Mill.) 'Ohio8245' with reduced catalase activity, due to the ex- 
pression of an antisense catalase gene, were more susceptible to CI than wild-type plants.

Soluble sugars and sugar alcohols are known to play important roles in protecting plants from stresses such as salinity, drought, and temperature (Rathinasabapathi, 2000). A number of research reports have focused on the development of CI and its symptoms, but the role and composition of soluble sugars associated with chilling tolerance have been studied far less. A number of osmoprotectants such as glycine betaine, proline, reducing sugars, and sugar alcohols are known to be up regulated in response to various stresses. One suggested function is to scavenge free radicals (Hayashi et al., 1997; Kishor et al., 1995; Shen et al., 1997a).

Mannitol is a well-characterized sugar alcohol. It is a significant photosynthetic product in some plant species, and has been shown to increase following abiotic stress (Zamski et al., 2001). Mannitol has also been suggested to act as an osmoprotectant by reacting with damaging hydroxyl radicals to form mannitol radicals, which are then converted to mannose in the presence of oxygen (Franzini et al., 1994; Shen et al., 1997b). Transgenic tobacco (Nicotiana tabacum L.) plants that express the mannitol1-phosphate dehydrogenase, $m t l D$, gene from $E$. coli accumulate increased levels of mannitol and are more tolerant of osmotic stress (Shen et al., 1997a, 1997b; Tarczynski et al., 1992). Studies with transgenic tobacco expressing a chloroplast localized $m t l D$ suggest that mannitol protects from oxidative damage during drought and chilling stress by protecting thiol-regulated enzymes such as phosphoribulokinase, thioredoxin, ferredoxin, and glutathione from hydroxyl radical damage (Shen et al., 1997b).

While Bruggemann et al. (1999) found that over expression of glutathione reductase in transgenic tomato produced no difference in chilling sensitivity of the photosynthetic apparatus, Sen et al. (1993) reported that transferring a gene from pea for chloroplastic $\mathrm{Cu} / \mathrm{Zn}$ superoxide dismutase improved tolerance to chill induced photoinhibition in tobacco. While more germane to freezing rather than CI, Pennycooke et al. (2003) demonstrated that down regulating $\alpha$-galactosidase in 'Mitchell' petunias resulted in an increase in endogenous raffinose and improved freezing tolerance by $4{ }^{\circ} \mathrm{C}$. Petunia and other CI susceptible horticultural crops are frequently grown in regions subject to cool spring and fall temperatures that can induce CI. Several horticultural species can benefit from gene modifications that impart potential to extend the growing season. Accordingly, we transformed a white-flowered nearly isogenic diploid petunia cultivar, 'Mitchell', and subjected the transformants to chilling stress to examine the impact of the $m t l D$ gene on CI in petunia. The study reported here investigated chilling tolerance using transgenic petunia plants with low and high mannitol levels due to ectopic expression of the mannitol-1-phosphate dehydrogenase gene ( $m t l D)$. Its impact on whole-plant symptom expression, membrane leakage, osmotic potential, and chilling induced alteration of soluble carbohydrate metabolism is presented.

\section{Materials and Methods}

Transformation OF PETUNIA PLANTS AND GROWTH CONDITIONS. Petunia $\times$ hybrida $\mathrm{cv}$. Mitchell was transformed using a modified leaf-disk Agrobacterium tumefaciens (Smith \& Towns.) Conn. (strain LBA 4404) cocultivation protocol published by Horsch et al. (1985). The genetic construct $p$ CaMVMTLDS contained the $35 \mathrm{~S}$ cauliflower mosaic virus promoter, the E. coli mtlD (mannitol-1-phosphate dehydrogenase) gene and a nopaline synthase termination signal subcloned into the binary vector $p \operatorname{Bin} 19$ (Tarczynski et al., 1992). Plants of each $\mathrm{T}_{0}$ transgenic line were allowed to flower and set seeds in a containment greenhouse. Two capsules of seed were collected from each transgenic line and germinated separately on MS medium (Schuler and Zielinski, 1989) containing $200 \mathrm{mg} \cdot \mathrm{L}^{-1}$ kanamycin. Numbers of green (kanamycin-resistance) and white (kanamycin-sensitive) seedlings $\left(\mathrm{T}_{1}\right)$ were counted after 3 weeks to test segregation for kanamycin resistance. Four transgenic lines (M2, M3, M8, and M9) segregated 3:1 (chi-square used as a statistical parameter) and were chosen for further use.

Expression of the $n p t I I$ gene was confirmed in $\mathrm{T}_{1}$ seedlings using an ELISA kit for the detection of neomycin phosphotransferase II (nptII, AGDIA, Elkhart, Ind.). Polymerase chain reaction (PCR) utilizing gene specific primers was conducted to confirm the presence of the $m t l D$ transgene in the putative $\mathrm{T}_{1}$ transformants following selection on kanamycin. Genomic DNA was extracted from leaves using a modified CTAB extraction method (Fulton et al., 1995). Fifty nanograms of genomic DNA was amplified using Taq Polymerase (Eppendorf, Hamburg, Germany) and 20 pmol each of the forward primer 5'GGGCAGGTGAAACGTAAAGA3' and the reverse primer 5'CAGTTTACGCAGTGGCTGAC3'. PCR was conducted for 35 cycles of denaturation at $92^{\circ} \mathrm{C}$ for 1 min, annealing at $60{ }^{\circ} \mathrm{C}$ for $1 \mathrm{~min}$, and extension at $72{ }^{\circ} \mathrm{C}$ for 1 min with a Mastercycler gradient thermocycler (Eppendorf). The PCR products were visualized following electrophoresis on a $0.8 \%$ agarose gel stained with ethidium bromide (data not shown).

Vegetative cuttings from a selected $\mathrm{T}_{1}$ plant of each transgenic line (M2, M3, M8, and M9) were rooted on MS media containing $100 \mathrm{mg} \cdot \mathrm{L}^{-1} \mathrm{kanamycin}$ to provide plant materials for replicated chilling trials. All excised shoots ( $2 \mathrm{~cm}$ vegetative cuttings) of $\mathrm{T}_{1}$ transgenic lines grew slower in the rooting medium containing $100 \mathrm{mg} \cdot \mathrm{L}^{-1} \mathrm{kanamycin}$ than wild-type (WT) shoots grown in the kanamycin-free rooting medium. To compensate for this delay, excised shoots of $\mathrm{T}_{1}$ transgenic lines were placed on the rooting medium containing kanamycin $4 \mathrm{~d}$ earlier than excised shoots of WT plants. Rooted plantlets of WT and $\mathrm{T}_{1}$ transgenic lines were transferred to potting medium (Fafard \#4; Conrad Fafard, Agawam, Mass.) after 2 weeks in tissue culture. Four- or 8 -week-old plants containing one to two flower buds were used in all experiments.

Plant growth And analysis. WT and transgenic plants were grown in a containment growth chamber at $25^{\circ} \mathrm{C}$ day $/ 20^{\circ} \mathrm{C}$ night, 12-h photoperiod, $60 \mu \mathrm{mol} \cdot \mathrm{m}^{-2} \cdot \mathrm{s}^{-1}$. Plants in all experiments were watered regularly and fertilized weekly with $13.5 \mathrm{~g} \cdot \mathrm{L}^{-1}$ Miracle Gro Nutriblend 21N-7.9P-14.9K (The Scotts Co., Marysville, Ohio). Each experiment was repeated three times.

At 4 weeks, three plants of WT and transgenic M2, M3, M8, and M9 for each of the three repetitions were harvested and divided into shoots and roots. Dry weight and root : shoot ratios were determined after $7 \mathrm{~d}$ drying at $75^{\circ} \mathrm{C}$ (Table 1).

Chilling TReatments. Eight-week-old plants of each line were separated into two groups. The control group (four plants for each line) remained in the growth chamber at $25^{\circ} \mathrm{C}$ day $/ 20^{\circ} \mathrm{C}$ night with a 12 -h photoperiod. The experimental chilled group was transferred to $3 \pm 0.5^{\circ} \mathrm{C}$ day $/ 0 \pm 0.5^{\circ} \mathrm{C}$ night, 12 -h photoperiod and $75 \%$ relative humidity for 3 weeks to induce chilling stress. Preliminary experiments were used to determine that 3 weeks chilling exposure provided better symptom expression than shorter intervals. After chilling treatments were completed, plants of both WT and transgenic lines were held at room temperature $\left(25 \pm 3{ }^{\circ} \mathrm{C}\right)$ for $24 \mathrm{~h}$ to develop symptoms. Visual injury, relative conductivity, osmotic potential, and carbohydrate content were then determined. 
Table 1. Dry weight and root: shoot ratios of wild type Petunia $\times$ hybrida and transgenic petunias expressing the E. coli $m t l D$ gene encoding mannitol-1-phosphate dehydrogenase (M2, M3, M8, M9). Plants were grown under nonchilling conditions at $25^{\circ} \mathrm{C}$ day $/ 20^{\circ} \mathrm{C}$ night with a 12 -h photoperiod. Data are means \pm SE of three plants. No significant differences were detected among means within columns based on Tukey's Studentized mean comparison test, $P<0.05$.

\begin{tabular}{lccc}
\hline $\begin{array}{l}\text { Plant } \\
\text { line }\end{array}$ & $\begin{array}{c}\text { Shoot } \\
(\mathrm{g} \text { dry wt })\end{array}$ & $\begin{array}{c}\text { Root } \\
(\mathrm{g} \text { dry wt })\end{array}$ & $\begin{array}{c}\text { Root : } \\
\text { shoot ratio }\end{array}$ \\
\hline WT & $4.04 \pm 0.20$ & $0.99 \pm 0.06$ & $0.29 \pm 0.02$ \\
M2 & $3.57 \pm 0.29$ & $1.03 \pm 0.09$ & $0.31 \pm 0.02$ \\
M3 & $3.61 \pm 0.18$ & $1.00 \pm 0.09$ & $0.31 \pm 0.01$ \\
M8 & $3.83 \pm 0.03$ & $1.02 \pm 0.11$ & $0.28 \pm 0.01$ \\
M9 & $3.38 \pm 0.24$ & $0.99 \pm 0.08$ & $0.30 \pm 0.02$ \\
\hline
\end{tabular}

Conductivity MEASurements. Two upper leaves from each plant line (WT, M2, M3, M8, M9) were removed $1 \mathrm{~d}$ after chilling treatment was completed. Ten disks $(0.5 \mathrm{~cm}$ diameter $)$ were taken from the tips of each leaf using a cork borer. The leaf disks were placed in measuring wells with $2 \mathrm{~mL}$ deionized water and electrolyte leakage was measured with a 100-well, ASAC-1000B Seed Analyzer (Neogen Corp.,Lansing, Mich.). Conductivity data was collected every $10 \mathrm{~min}$ for $240 \mathrm{~min}$ to determine sample leakage $\left(\mathrm{L}_{1}\right)$. Conductivity was also measured from leaf disks frozen in liquid nitrogen to determine total leakage $\left(\mathrm{L}_{2}\right)$. Relative injury represented by the mean leakage of leaf disks at each time point, as a percentage of the maximum leakage from liquid nitrogen killed leaf disks was calculated as: $\left(\mathrm{L}_{1} / \mathrm{L}_{2} \times 100 \%\right)$. Regression of relative injury over $120 \mathrm{~min}$ from a time course leakage assay was used to examine slopes as indicators of chilling-induced permeability for stressed and nonstressed samples.

Measurements of osmotic Potential. Whole equal-sized upper leaves without petioles were collected from WT and transgenic plants and frozen in liquid nitrogen. Frozen leaves were thawed and pulverized with a mortar and pestle, and $20 \mu \mathrm{L}$ of the leaf extract was assayed. Osmotic potential was measured with a Model 5520, Wescor vapor pressure osmometer (Wescor, Logan, Utah) at the end of the chilling treatment.

Carbohydrate EXTRACTION AND ANALYSIS. At the end of the chilling treatment, fresh upper leaves $\left(\approx 4-5 \mathrm{~cm}^{2}\right)$ were randomly harvested from three control plants and three chill-stressed plants for each line (WT, M2, M3, M8, M9). Leaves were plunged into liquid nitrogen, freeze-dried and stored over silica gel in a desiccator at $-20{ }^{\circ} \mathrm{C}$ until use. Freeze-dried samples were ground with a mortar and pestle and screened through a 100-mesh sieve to ensure uniformity of particle size. About $1 \mathrm{mg}$ of screened sample was solubilized in $1 \mathrm{~mL} 100 \mathrm{~mm} \mathrm{NaOH}$ at $4{ }^{\circ} \mathrm{C}$ for 30 min, centrifuged $5 \mathrm{~min}$ at $1000 \mathrm{~g}_{\mathrm{n}}$ and filtered through a $0.22-\mu \mathrm{M}$ Whatman Nylon 66 syringe filter. The filtrate was analyzed for carbohydrate content with a Dionex DX-300 series HPLC system (Sunnyvale, Calif.) equipped with a $25-\mu$ Linjection loop, a pulsed electrochemical detector, and a CarboPac-100 analytic column maintained with a column heater at $35^{\circ} \mathrm{C}$. An eluant gradient was used to optimize oligosaccharide separation; $\mathrm{NaOH}$ concentration was linearly increased from 70 to $120 \mathrm{~mm}$ in $18 \mathrm{~min}$, combined with $3.0 \mathrm{~mm}$ sodium acetate for $10 \mathrm{~min}$, then increased to $35 \mathrm{~mm}$ sodium acetate for the last $8 \mathrm{~min}$, as per Hamman et al. (1996). External standards obtained from Sigma-Aldrich (St. Louis) were used to calculate concentration of all sugars and polyols.

\section{Results}

Four transgenic lines that segregated 3:1 for kanamycin resistance, as determined by the ability to germinate and grow on MS media containing $200 \mathrm{mg} \cdot \mathrm{L}^{-1}$ kanamycin, were selected for further evaluation. The presence of the nptII gene product was confirmed in these plants using ELISA (data not shown) and the $m t l D$ gene was present in all kanamycin resistant $\mathrm{T}_{1}$ plants from the four lines selected as determined by PCR (data not shown). The $m t l D$ gene was not detected in WT petunia plants (data not shown). While kanamycin delayed rooting in the transgenic plants compared to WT plants started on kanamycin-free media, growth rates were similar once plants were established in potting medium. Shoot and root dry weights of 4-week-old WT and transgenic plants did not differ significantly (Table 1).

VISUAL CHILLING SYMPTOMS OF PLANTS. Exposure of 8-weekold WT and $\mathrm{T}_{1}$ transgenic plants (M2, M3, M8, M9) to 3 weeks at $3{ }^{\circ} \mathrm{C}$ day $/ 0{ }^{\circ} \mathrm{C}$ night (12-h photoperiod) resulted in visible leaf and whole-plant wilting after transfer to $25 \pm 3.0^{\circ} \mathrm{C}$ for $24 \mathrm{~h}$. M3 and M8 regained turgor or remained turgid, and only a few leaves showed necrosis (Fig. 1). Eight-week-old plants were chosen for this experiment because this was the first stage at which flower-bud development was noticed. Flowering was suppressed (data not shown) and there were no visual differences in floral development among WT and transgenic lines during the chilling period.

RELATIVE CONDUCTIVITY AND MEMBRANE LEAKAGE OF CHILLED PLANTS. Expanded upper leaves of approximately the same size were collected $1 \mathrm{~d}$ after transfer of chilled plants to $25 \pm 3.0^{\circ} \mathrm{C}$, and leaf samples of nonchilled plants were collected at the same time, directly from the $25^{\circ} \mathrm{C}$ growth chamber. Leakage rates derived from time course regression analyses for relative conductivity of nonchilled control plants (WT, M2, M3, M8, M9) did not differ significantly (Fig. 2). However, relative conductivity of chilled transgenic lines M3 and M8 was significantly lower than WT, M2, and M9 (Fig. 3). Lower leakage rates were detected in chilled transgenic lines M3 and M8 compared to the low-mannitol containing transgenic and WT lines (Fig. 3), suggesting membrane stabilization occurred in the stressed high-mannitol containing lines.

Osmotic Potential of Chilled Plants. Osmotic potential of leaf samples did not differ between WT and transgenic lines under nonchilling treatments, nor did they differ between WT and transgenic lines following chilling treatment (Fig. 4). However, the osmotic potentials of nonchilled plants were significantly higher $(\approx 0.4 \mathrm{MPa})$ when compared with those of chilled plants.

SOlUble CaRbohydRaTES. No significant differences were detected in the inositol, glucose, fructose, sucrose, raffinose, or stachyose levels in control WT vs. transgenic plants. Mannitol was the only soluble sugar that differed in the nonstressed transgenic plants, and it was consistently higher in the $m t l D$ transgenic lines M3 and M8 (Table 2). Mannitol content of transgenic lines M3 and M8 was $\approx 3 \times$ that of WT and the transgenic lines designated M2 and M9. Mean mannitol levels of transgenic lines M2 and M9 were slightly higher than that of WT, but the differences were not significant. The other soluble carbohydrates measured did not differ between the low- and high-mannitol containing lines.

Carbohydrate metabolism was altered in plants exposed to chilling stress in both low- and high-mannitol containing lines. Except for raffinose, soluble carbohydrates of both WT and transgenic lines generally decreased following chilling. Even though mannitol levels of WT and all transgenic lines declined 


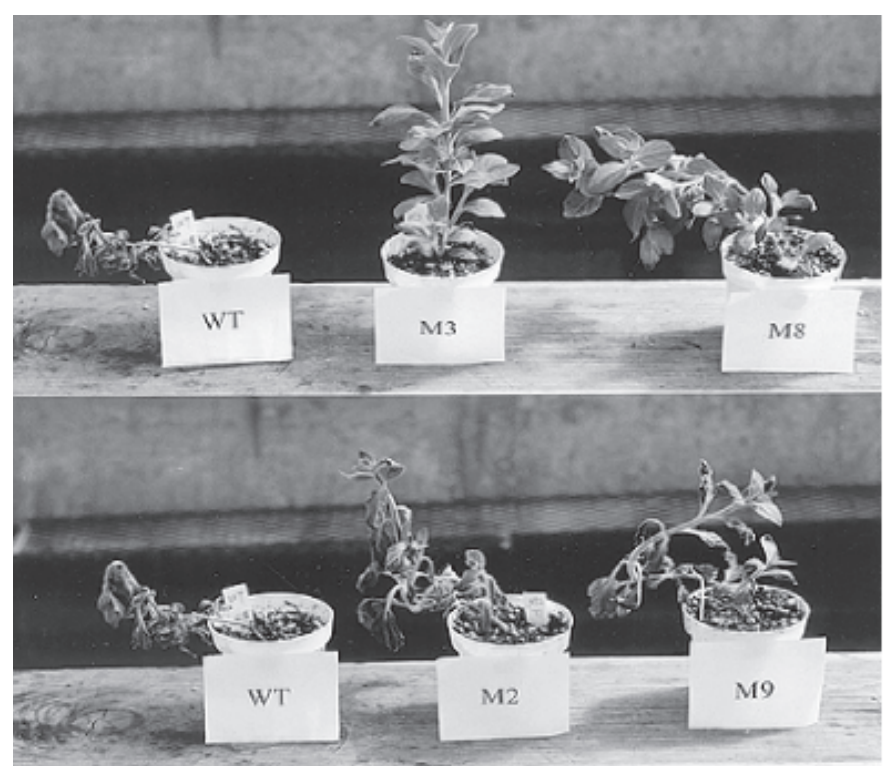

Fig. 1. Visual symptoms of chilling injury in wild type (WT) and transgenic petunia plants expressing the E. coli $m t l D$ gene (lines M2, M3, M8, and M9) encoding mannitol-1-phosphate dehydrogenase. Photographs were taken after $24 \mathrm{~h}$ at $25^{\circ} \mathrm{C}$ following a $21-\mathrm{d}$ exposure to chilling stress at $3{ }^{\circ} \mathrm{C} /$ day and $0{ }^{\circ} \mathrm{C}$ night, with a $12-\mathrm{h}$ photoperiod.

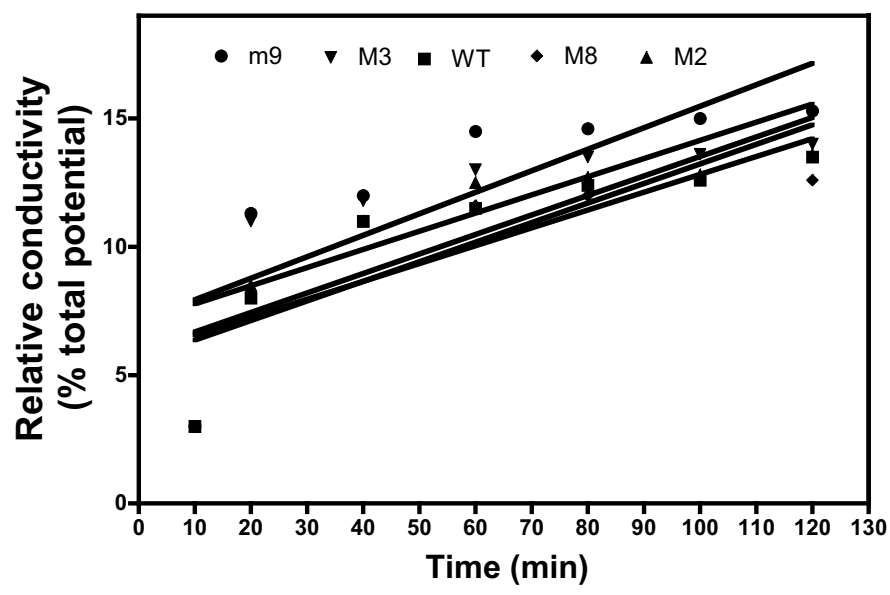

Fig. 2. Time course conductivity showing leakage rate of exosmosed cell sap from control, non-chill-stressed wild-type (WT) and $m t l D$ transgenic (M2, M3, M8, M9) petunia leaf disks. Leaf samples were collected and assayed after $22 \mathrm{~d}$ at $25^{\circ} \mathrm{C}$ day $/ 20^{\circ} \mathrm{C}$ night with a $12-\mathrm{h}$ photoperiod. Differences between slopes are not significantly different. Slopes and $\left(r^{2}\right)$ are: $\mathrm{M} 9=0.08(0.6220) ; \mathrm{M} 2=0.0 .07$ $(0.6913) ; \mathrm{WT}=0.08(0.7291) ; \mathrm{M} 3=0.07$ (0.5649); M8 $=0.07$ (0.6650).

during chilling, the mannitol content of transgenic lines M3 and M8 remained $\approx 8 \times$ higher than WT, M2, and M9 following chilling treatment (Table 2). In addition, fructose, sucrose, and raffinose levels were consistently higher in the high-mannitol containing lines following chilling stress, while inositol, glucose and stachyose did not differ (Table 2).

\section{Discussion}

Tobacco plants have previously been transformed with the bacterial gene encoding mannitol-1-dehydrogenase $(m t l D)$. While the expression of this gene in E. coli leads to mannitol catabolism, its ectopic expression in transgenic tobacco leads to the increased production and accumulation of mannitol (Tarczynski et al.,
1992). These plants have provided a useful experimental system for studying the role of sugar alcohols in abiotic stress protection, and transgenic tobacco plants containing higher mannitol have increased tolerance to salt and drought stress (Shen et al., 1997a, 1997b; Tarczynski et al., 1992). Karakis et al. (1997) found that tobacco transformed with $m t l D$ osmotically adjusted to salt stress, but not to drought stress. In their study the growth rate and size of transformed plants were reduced compared to control plants. In contrast, we did not detect any growth reduction in nonstressed petunia plants transformed with $m t l D$ (Table 1).

While salinity and drought can be major limitations to crop productivity, chilling temperatures can also have a negative impact on horticultural crops. To investigate the role of mannitol during chilling stress, the $m t l D$ gene from $E$. coli was transformed into petunia. Four transgenic lines containing the $m t l D$ gene were identified. Two of those lines (high-mannitol lines; M3 and M8) had mannitol levels that were higher than nontransformed WT plants, while two transgenic lines (low-mannitol lines; M2 and M9) had mannitol levels similar to those detected in WT plants.

Following chilling stress treatments, the high-mannitol containing transgenic lines M3 and M8 had fewer chilling injury symptoms at $25{ }^{\circ} \mathrm{C}$ than the WT and low-mannitol containing transgenic lines M2 and M9. Only a few M3 or M8 plants wilted or had necrotic leaves when chilled compared to other lines. Death or stunted growth was observed in the chilled WT and in transgenic lines M2 and M9, but M3 and M8 showed continuous growth and some plants flowered $\approx 10 \mathrm{~d}$ after transfer to the greenhouse (data not shown). These visual observations were also consistent with leakage conductivity data, as the high-mannitol transgenic lines had less leakage following chilling. Electrolyte leakage from leaves is considered a reliable estimate of cell disruption and membrane integrity and is often used as a reliable measure of chilling injury (Kuk et al., 2003; Wolk and Herner, 1982).

Because ROS are known to cause membrane lipid peroxidation by increased formation of malondialdehyde and protein degradation by promotion of intra-and inter molecular crosslinking from protein fragmentation and disulfide bonding, it is not unreasonable to assume that a protective function of ROS scavengers may alleviate membrane disruption (Shen et al., 1997b; Stadtman, 1992). Although the accumulation site of mannitol in these transgenics was not investigated, better recovery and less leakage in the high mannitol containing lines suggests a possible membrane protective function. Calculation of osmotic potential using the Van't Hoff equation, $(\mathrm{R}=-\mathrm{ciRT})$ indicates that the osmotic potential of mannitol produced in chilled M3 and M8 plants is 0.0005 , and $0.0006 \mathrm{MPa}$, respectively (assuming 90\% water content in leaf and $\mathrm{T}=279^{\circ} \mathrm{K}$ ). The osmotic potentials generated from accumulated mannitol of transgenic line M3 and M8 are roughly $0.04 \%$ and $0.06 \%$ of osmotic potentials generated from all solutes. Thus, mannitol is not likely a primary osmolyte for osmotic adjustment and should rather be considered as an osmoprotectant in these transgenic petunia lines.

According to Saltveit (2000), significant correlations between changes in chilling sensitivity and compositional changes in sugars and organic acids have not been found. The data reported here showed that chilling caused a shift of carbohydrate metabolism in WT and transgenic petunias (Table 2). However, a positive correlation between soluble sugar levels and chilling was not observed, unlike the significant correlations found between soluble carbohydrate levels in plants and their cold hardiness (Fischer and Holl, 1991; Imanishi et al., 1998; Stushnoff et al., 1993). Since chilling stress may or may not trigger cold acclimation, does not involve 


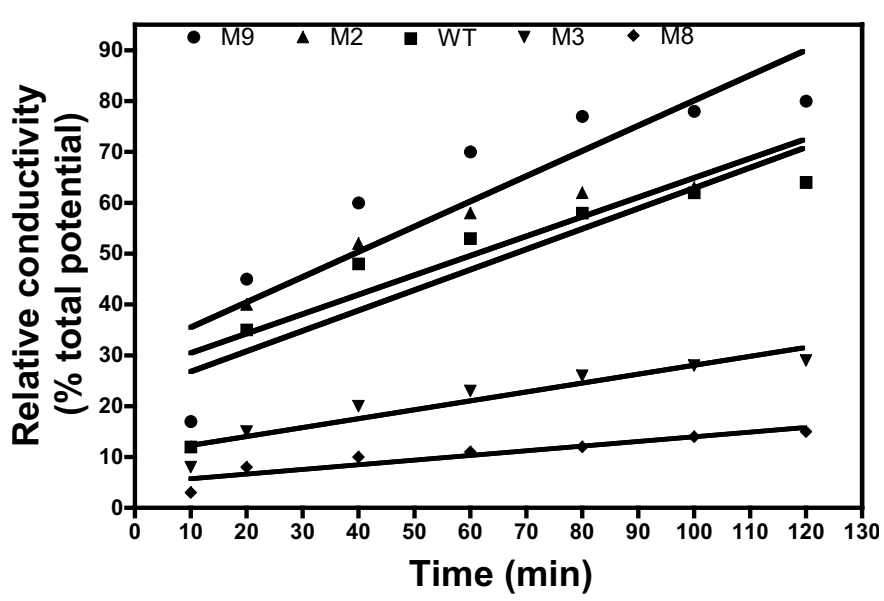

Fig. 3. Time course conductivity showing leakage rate of exosmosed cell sap from chilled wild-type (WT) and transgenic (M2, M3, M8, M9) petunia leaf disks. Leaf samples were collected and assayed after $21 \mathrm{~d}$ of chilling stress treatment $\left(3{ }^{\circ} \mathrm{C}\right.$ days and $0{ }^{\circ} \mathrm{C}$ nights, 12 -h photoperiod) followed by $24 \mathrm{~h}$ at $25^{\circ} \mathrm{C}$. Differences between slopes are significantly different $(P=0.01)$. Slopes and $\left(r^{2}\right)$ are: $\mathrm{M} 9=0.49(0.7795) ; \mathrm{M} 2=0.38(0.6960) ; \mathrm{WT}=0.40(0.7956) ; \mathrm{M} 3$ $=0.17(0.8912) ; \mathrm{M} 8=0.09(0.8695)$.

ice nucleation, and is thus quite different from freezing stress in the presence of ice, correlations between soluble carbohydrate level/composition and chilling tolerance should not necessarily be expected. Nonetheless, some studies have shown a positive correlation between soluble carbohydrate level/composition and chilling tolerance (Purvis and Rice, 1983; Taylor et al., 1972). Maintenance of adequate sugar supplies in tomato was found to be associated with better growth at chilling temperatures (King et al., 1988). In this study, chilled high-mannitol containing plants (M3, M8) had higher mannitol, sucrose and raffinose levels than WT and low-mannitol containing transgenic lines (M2 and M9), and were less susceptible to chilling injury.

The diversion of carbon to sugar alcohol biosynthesis under abiotic stress has been reported by Bohnert et al. (1995). Myoinositol serves as a source of raffinose, stachyose, and verbascose. In this study inositol dropped and raffinose increased in response

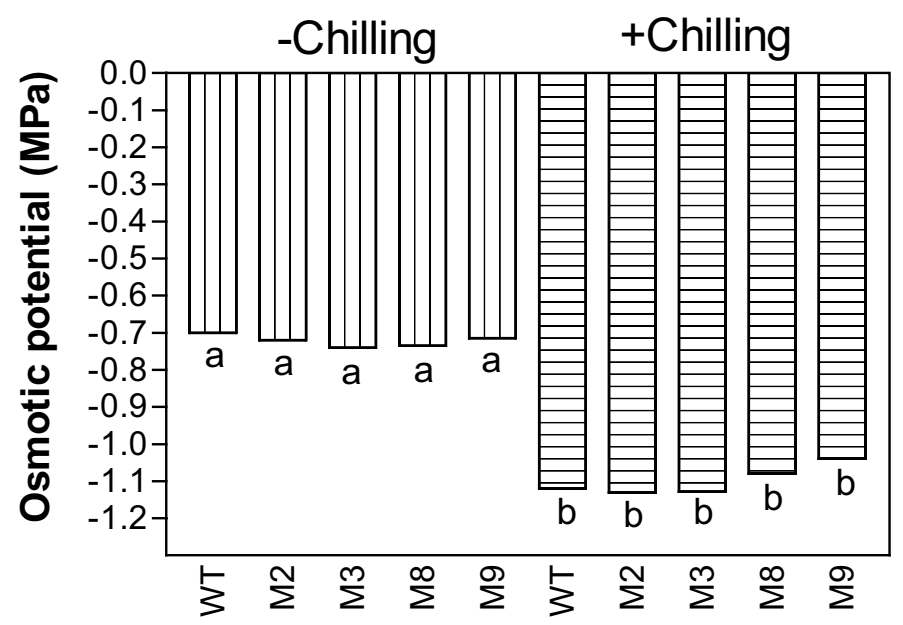

Fig. 4. Osmotic potential of control (nonchilled) and chilled wild-type and transgenic (M2, M3, M8, M9) plants. Control plants were grown $22 \mathrm{~d}$ at $25^{\circ} \mathrm{C}$ days $/ 20^{\circ} \mathrm{C}$ nights with a 12 -h photoperiod, while chilled plants were sampled after $24 \mathrm{~h}$ at $25^{\circ} \mathrm{C}$ following a $21-\mathrm{d}$ exposure to chilling stress at $3{ }^{\circ} \mathrm{C}$ days and $0{ }^{\circ} \mathrm{C}$ nights. Data are means (SE are too small for visibility on bars) from three separate experiments. Means followed by the same letter are not significantly different at $P<0.05$ by Tukey's Studentized comparison test. to the cooler temperatures used to chill the plants. Glucose, fructose, and sucrose levels were similar in all nonchilled plants, but fructose and sucrose levels were lower in the chilled, lowmannitol containing group than in the chilled high-mannitol containing group (Table 2). Since fructose, glucose, and sucrose are important substrates in plant metabolism, maintenance of these soluble sugars may also enhance tolerance of the high-mannitol containing plants to chilling stress.

Mannitol was the only soluble carbohydrate altered by transformation; thus, its possible role as a free radical scavenger or mediator of carbohydrate metabolism under chilling treatments cannot be neglected. If mannitol shields chilling-treated plants from the attack of ROS on membranes, nucleic acids, proteins and other cellular components, or acts in some other equally unknown fashion to alter metabolism, it might be expected that rates of photosynthesis and respiration could be sustained more effectively in the high-mannitol containing plants at chilling temperatures. Transgenic petunia plants expressing higher mannitol levels possessed a greater capacity to tolerate severe, longterm chilling stress than that of wild-type and transgenic lines with lower mannitol levels. Mannitol content in high-mannitol lines was not adequate to protect by osmotic adjustment caused by chilling stress. Mannitol is therefore more likely to function as a free radical scavenger or osmoprotectant, rather than an osmoregulator.

Flowering was arrested in all lines during chilling (data not shown), similar to observations by Caulfield and Bounce (1988) and Wang and Baker (1979). In high-mannitol containing lines flowering resumed following the return to nonchilling temperatures. The incorporation of the $m t l D$ gene into important bedding plants like petunia has the potential to extend their growing season, making it possible to plant earlier in the spring, as well as to maintain enhanced flower display later in autumn. While petunia was used as a model floriculture crop, this technology is potentially transferable to other crops and could be used to enhance chilling tolerance of a diverse array of annuals in the landscape provided gene expression and plant response outdoors is similar to that detected under controlled-environment conditions. The $m t l D$ gene can be added to the list of metabolic regulators that may influence plant responses to chilling stress.

\section{Literature Cited}

Alscher, R.G., N.R. Madamanchi, and C.L. Cramer. 1991. Protective mechanisms in the chloroplast stroma, p. 145-155 In: E.J. Pell and K.L. Steffen (eds.). Active oxygen/oxidative stress and plant metabolism. Amer. Soc. Plant Physiologists, Rockville, Md.

Bohnert, H.J., D.E. Nelson, and R.G. Jensen. 1995. Adaptations to environmental stresses. Plant Cell 7:1099-1111.

Bruggemann, W., V. Beyel, M. Brodka, H. Poth, M. Weil, and J. Stockkhaus. 1999. Antioxidants and antioxidative enzymes in wild-type and transgenic Lycopersicon genotypes of different chilling tolerance. Plant Sci. 140:145-154.

Burden, R.H., V. Gill, P.A. Boyd, and D. Okane. 1994. Chilling, oxidative stress and antioxidant enzyme responses in Arabidopsis thaliana. Proc. Royal Soc. Edinburgh 102B:177-185.

Caulfield, F. and J.A. Bounce. 1988. Comparative responses of photosynthesis to growth temperature in soybean (Glycine max L. Merrill) cultivars. Can. J. Plant Sci. 68:419-425.

Fischer, C. and W. Holl. 1991. Food reserves of scots pine (Pinus sylvestris $\mathrm{L}$.): I. Seasonal changes in the carbohydrates and fat reserves of pine needles. Trees 5:187-195.

Franzini, E., H. Sellak, J. Hakim, and C. Pasquier. 1994. Comparative sugar degradation by $(\mathrm{OH})$ produced by the ion-driven Fenton reaction and gamma radiolysis. Arch. Biochem. Biophys. 309:261-265. 
Table 2. Carbohydrate content $\left(\mu \mathrm{mol} \cdot \mathrm{g}^{-1}\right.$ dry weight) of wild-type (WT) Petunia $\times$ hybrida and transgenic petunias expressing the E. coli mtlD gene encoding mannitol-1-phosphate dehydrogenase (M2, M3, M8, M9) subjected to nonchilling and chilling conditions. Control (nonchilled) plants were grown for $22 \mathrm{~d}$ under $25^{\circ} \mathrm{C}$ day $/ 20^{\circ} \mathrm{C}$ night with a 12-h photoperiod and chilled plants were grown for $21 \mathrm{~d}$ under $3{ }^{\circ} \mathrm{C}$ days and $0{ }^{\circ} \mathrm{C}$ nights with a 12 -h photoperiod followed by $24 \mathrm{~h}$ at $25^{\circ} \mathrm{C}$.

\begin{tabular}{llccccccc}
\hline $\begin{array}{l}\text { Chilling } \\
\text { treatment }\end{array}$ & \multicolumn{1}{c}{ Group } & Inositol & Mannitol & Glucose & Fructose & Sucrose & Raffinose & Stachyose \\
\hline No & WT & $9.39 \mathrm{a}^{\mathrm{z}}$ & $0.86 \mathrm{c}$ & $23.54 \mathrm{a}$ & $42.95 \mathrm{a}$ & $23.75 \mathrm{a}$ & $1.85 \mathrm{a}$ & $0.83 \mathrm{a}$ \\
No & Low-mannitol & $9.78 \mathrm{a}$ & $1.14 \mathrm{c}$ & $23.13 \mathrm{a}$ & $48.06 \mathrm{a}$ & $22.88 \mathrm{a}$ & $2.53 \mathrm{a}$ & $0.65 \mathrm{a}$ \\
& $\begin{array}{l}\text { (M2, M9) } \\
\text { No }\end{array}$ & & & & & & & \\
& High-mannitol & $10.63 \mathrm{a}$ & $3.39 \mathrm{a}$ & $20.64 \mathrm{ab}$ & $49.83 \mathrm{a}$ & $25.82 \mathrm{a}$ & $2.5 \mathrm{a}$ & $0.64 \mathrm{a}$ \\
Yes & (M3, M8) & & & & & & & \\
Yes & WT & $6.46 \mathrm{~b}$ & $0.23 \mathrm{c}$ & $17.54 \mathrm{c}$ & $36.43 \mathrm{~b}$ & $11.25 \mathrm{~b}$ & $5.08 \mathrm{~b}$ & $0.62 \mathrm{a}$ \\
& Low-mannitol & $5.05 \mathrm{~b}$ & $0.26 \mathrm{c}$ & $18.07 \mathrm{bc}$ & $35.72 \mathrm{~b}$ & $11.51 \mathrm{~b}$ & $5.06 \mathrm{~b}$ & $0.45 \mathrm{a}$ \\
Yes & (M2, M9) & & & & & & & \\
& High-mannitol & $4.58 \mathrm{~b}$ & $2.18 \mathrm{~b}$ & $20.08 \mathrm{ab}$ & $50.22 \mathrm{a}$ & $19.33 \mathrm{a}$ & $6.15 \mathrm{c}$ & $0.50 \mathrm{a}$
\end{tabular}

$\overline{{ }^{2} \text { Data are means of three replications. Means followed by the same letter within each column are not significantly different }}$ at $P<0.05$ using Tukey's Studentized comparison test.

Fulton, T.M., J. Chunwongse, and S.D. Tanksley. 1995. Microprep protocol for extraction of DNA from tomato and other herbaceous plants. Plant Mol. Biol. Rpt. 13:207-209.

Hamman, R.A. Jr., I.E. Dami, T.M. Walsh, and C. Stushnoff. 1996. Seasonal carbohydrate changes and cold hardiness of Chardonnay and Riesling grapevines. Amer. J. Enol. Viticult. 47:31-36.

Hayashi, H., L. Mustardy, P. Deshnium, M. Ida, and N. Murata. 1997. Transformation of Arabidopsis thaliana with the codA gene for choline oxidase; accumulation of glycine betaine and enhanced tolerance to salt and cold stress. Plant J. 12(1):133-142.

Horsch, R.B., J.E. Fry, N.L. Hoffmann, D. Eichholtz, S.G. Rogers, and R.T. Fraley. 1985. A simple and general method for transferring genes into plants. Science 227:1229-1231.

Imanishi, H.T., T. Suzuki, K. Masuda, and T. Harada. 1998. Accumulation of raffinose and stachyose in shoot apices of Lonicera caerulea L. during cold acclimation. Scientia Hort. 72:255-263.

Karakis, B., P. Ozias-Akins, C. Stushnoff, M. Seufferheld, and M. Rieger. 1997. Salinity and drought tolerance of mannitol-accumulating transgenic tobacco. Plant Cell Environ. 20:609-616.

Kerdnaimongkol, K. and W.R Woodson. 1999. Inhibition of catalase by antisense RNA increases susceptibility to oxidative stress and chilling injury in transgenic tomato plants. J. Amer. Soc. Hort. Sci. 124:330-336.

King, A.I., D.C. Joyce, and M.S. Roberson. 1988. Roles of carbohydrates in diurnal chilling sensitivity of tomato seedlings. Plant Physiol. 86:764-768.

Kishor, K.P.B.,Z.Hong, G.H. Miao, C.A.A.Hu, and D.P.S. Verma. 1995. Overexpression of $\Delta^{1}$-pyrroline-5-carboxylate synthetase increases proline production and confers osmotolerance in transgenic plants. Plant Physiol. 108:1387-1394.

Kuk,Y.I., J.H. Lee, H.Y. Kim, S.J. Chung, G.C. Chung, J.O. Guh, H.J. Lee, and N.R. Burgos. 2003. Relationships of cold acclimation and antioxidative enzymes with chilling tolerance in cucumber (Cucumis sativus L.). J. Amer. Soc. Hort. Sci. 128:661-666.

Lyons, J.M. 1973. Chilling injury in plants. Annu. Rev. Plant Physiol. 24:445-466.

Pennycooke, J.C., M.L. Jones, and C. Stushnoff. 2003. Down-regulating $\alpha$-galactosidase enhances freezing tolerance in transgenic petunia. Plant Physiol. 133:901-909.

Prasad, T.K., M.D. Anderson, B.A. Martin, and C.R. Steward. 1994. Evidence for chilling-induced oxidative stress in maize seedlings and a regulatory role for hydrogen peroxide. Plant Cell 6:65-74.

Purvis, A.C. and J.D. Rice. 1983. Low temperature induction of invertase activity in grapefruit flavedo tissue. Phytochemistry 22(4):831-834.

Rathinasabapathi, B. 2000. Metabolic engineering for stress tolerance: Installing osmoprotectant synthesis pathways. Ann. Bot. 86:709-716.
Salveit, M.E. 2000. Discovery of chilling injury, p. 423-448. In: S.D. Kung and S.F. Yang (eds.). Discoveries in plant biology. vol. 3. World Scientific Publishing Co., Singapore.

Saltveit, M.E. and L.L. Morris. 1990. Overview on chilling injury of horticultural crops, p. 3-15. In: C.Y. Wang (ed.). Chilling injury of horticultural crops. CRC Press, Boca Raton, Fla.

Schuler, M.A. and R.E. Zielinski. 1989. Methods in plant molecular biology. Academic, San Diego.

Sen, G.A., R.P. Webb, A.S. Holaday, and R.D. Allen. 1993. Overexpression of superoxide dismutase protects plants from oxidative stress. Plant Physiol. 103:1067-1074.

Shen, B., R.G. Jensen, and H.J. Bohnert. 1997a. Mannitol protects against oxidation by hydroxyl radicals. Plant Physiol. 115:527-532.

Shen, B., R.G. Jensen, and H.J. Bohnert. 1997b. Increased resistance to oxidative stress in transgenic plants by targeting mannitol biosynthesis to chloroplast. Plant Physiol. 113:1177-1183.

Stadtman, E.R. 1992. Protein oxidation and aging. Science 257:12201224.

Stushnoff, C., R.L. Remmele, V. Essensee, and M. McNeil. 1993. Low temperature induced biochemical mechanisms, implications for cold acclimation and de-acclimation. North Atlantic Treaty Organization Adv. Sci. Inst. Ser. I. Global Environmental Change 16:647-657.

Tarczynski, M.C., R.G. Jensen, and H.J. Bohnert. 1992. Expression of a bacterial $m t l D$ gene in transgenic tobacco leads to production and accumulation of mannitol. Proc. Natl. Acad. Sci. USA. 89:2600-2604.

Taylor, A.O., N.M. Jepsen, and J.T. Christeller. 1972. Plants under climatic stress III. Low temperature, high light effects on photosynthetic products. Plant Physiol. 49:798-802.

Walker M.A., V.J. Oakley, and B.D. McKersie. 1991. The role of free radical scavenging systems and regulation of photosynthetic electron transport in chilling resistance of tomato, p. 216-219. In: E.J. Pell and K.L. Steffen (eds.). Active oxygen/oxidative stress and plant metabolism. Amer. Soc. Plant Physiologists, Rockville, Md.

Wang, C.Y. and J.E. Baker. 1979. Effects of two free radical scavengers and intermittent warming on chilling injury and polar lipid composition of cucumber and sweet pepper fruits. Plant Cell Physiol. 20:243-251.

Wise, R.R. and A.W. Naylor. 1987. Chilling-enhanced photooxidation. The peroxidative destruction of lipids during chilling injury to photosynthesis and ultrastructure. Plant Physiol. 83:272-284.

Wolk, W.D. and R.C. Herner. 1982. Chilling injury of germinating seeds and seedlings. HortScience 17:169-173.

Zamski, E., W-W. Guo, Y.T. Yamamoto, D. Mason Pharr, and J.D. Williamson. 2001. Analysis of celery (Apium graveolens) mannitol dehydrogenase $(M t d)$ promoter regulation in Arabidopsis suggests roles for MTD in key environmental and metabolic responses. Plant Mol. Biol. 47:621-631. 